Universidade Tecnológica Federal do Paraná - UTFPR

Campus Ponta Grossa - Paraná - Brasil

ISSN: 1981-3686/v. 04, n. 02, p.153-160, 2010

DOI: $10.3895 / \mathrm{S} 1981-36862010000200004$

\author{
Revista Brasileira de Tecnologia \\ Agroindustrial
}

\title{
QUALIDADE NUTRICIONAL DE RAÇÕES SECAS PARA CÃES ADULTOS COMERCIALIZADAS EM LAJEADO-RS.
}

\section{NUTRITIONAL QUALITY OF DRY FOODS FOR ADULT DOGS MARKETED IN LAJEADO-RS.}

\author{
Cleimar Vedoy da Silva ${ }^{1}$; Francisco de Barros ${ }^{2}$; Claucia Fernanda Volken de Souza ${ }^{3}$ \\ ${ }^{1}$ Centro Universitário - Univates - Lajeado cleimar_silva@ universo.univates.br \\ ${ }^{2}$ Centro Universitário - Univates - Lajeado chicobarros@ universo.univates.br \\ ${ }^{3}$ Centro Universitário - Univates - Lajeado clauciavolken@ bol.com.br
}

\section{Resumo}

A produção e a qualidade das rações caninas brasileiras aumentaram significativamente nos últimos anos. No Brasil o Ministério da Agricultura, Pecuária e Abastecimento é responsável pela regulamentação das rações para cães, fixando padrões de qualidade a fim de diminuir a variação entre os diferentes fabricantes de rações comerciais. Portanto, o objetivo desse trabalho foi avaliar a qualidade nutricional de rações secas para cães adultos dos tipos combate, premium e super premium comercializadas em Lajeado - RS, comparando com os valores indicados nos rótulos das mesmas e limites estabelecidos pela legislação brasileira. Para isso, foram coletadas amostras de rações secas para cães adultos, comercializadas em pet shops da cidade, que foram submetidas às análises físico-químicas de umidade, cinzas, lipídios e proteína. A composição nutricional de $100 \%$ das rações secas para cães adultos dos tipos combate, premium e super premium estavam em conformidade com os valores indicados nos rótulos das mesmas. Os teores de proteína e lipídios diferiram acentuadamente entre os três tipos de rações avaliados, principalmente entre os segmentos combate e super premium. Tais diferenças são conseqüência da qualidade dos ingredientes empregados em cada uma delas. Apenas uma amostra estava em desacordo com o limite mínimo de lipídios estabelecido pela legislação brasileira. Os resultados obtidos indicam a qualidade dessas rações, que é de extrema importância para os cães que as consomem, uma vez que estas podem ser consideradas alimentos completos para os animais e, por isso, serem utilizadas como fonte única de alimentação para os cães.

Palavras-chave: avaliação nutricional, rações, cães, qualidade.

\section{Introdução}

A indústria brasileira de rações para cães e gatos apresentou um crescimento significativo nos últimos anos. A produção nacional passou de 1,15 para 1,93 milhões de toneladas entre os anos de 2001 e 2009, respectivamente, o que representa uma elevação de aproximadamente $68 \%$ em oito anos (SINDIRAÇÕES, 2010). 
Aliado a isso, nos últimos dez anos tem se verificado um incremento na qualidade das rações produzidas no Brasil. A ciência da nutrição canina desenvolveu-se e rações com níveis adequados de nutrientes para as diversas classes de tamanho do corpo e fases do ciclo vital foram lançadas no mercado (MALAFAIA et al., 2002). As rações comerciais para cães podem ser classificadas em combate, econômica, padrão, premium e super premium, de acordo com a matériaprima utilizada na fabricação (CASE et al., 1998).

A qualidade é objetivo em todos os ramos da indústria. Se, por um lado, este fator é responsável pela busca do aperfeiçoamento contínuo, por outro, assegura a sobrevivência na competitividade entre os mercados. A qualidade de um produto, definida como sua adequação ao uso ao qual se destina, pode ser garantida por muitas medidas, as quais se resumem na aplicação de tecnologias seguras a matérias-primas de boa qualidade. $\mathrm{O}$ monitoramento das características de produtos e processos pode ser implementado por meio de muitas ferramentas analíticas, entre as quais os métodos físico-químicos destacam-se como rápidos e objetivos (BERTOLINO, 2010).

O Ministério da Agricultura, Pecuária e Abastecimento, é o responsável pela regulamentação das rações para cães e gatos no Brasil, conforme Decreto $\mathrm{N}^{\circ}$ 6296, de 11 de dezembro de 2007 (BRASIL, 2007). A Instrução Normativa N 9, de 09 de julho de 2003, que regulamenta os padrões de identidade e qualidade de alimentos completos destinados a cães, fixa limites em relação aos parâmetros de qualidade que devem ser obrigatoriamente seguidos pelas indústrias desse segmento (BRASIL, 2003). Já a Instrução Normativa $\mathrm{N}^{\circ}$ 30, de 05 de agosto de 2009, estabelece critérios e procedimentos para rotulagem de produtos destinados à alimentação de animais de companhia (BRASIL, 2009).

Nesse contexto, o objetivo desse trabalho foi avaliar a qualidade nutricional de rações secas para cães adultos dos tipos combate, premium e super premium comercializadas em Lajeado - RS, comparando com os valores indicados nos rótulos das mesmas e limites estabelecidos pela legislação brasileira.

\section{Material e Métodos}

No período de agosto a novembro de 2009 , foram coletadas nove amostras de rações secas para cães adultos para fins de determinação da qualidade nutricional. As rações analisadas eram de três marcas comerciais diferentes, sendo que de cada uma delas foram avaliadas os tipos combate, premium e super premium. Todas as amostras foram adquiridas em pet shops da cidade de Lajeado RS. 
Foram realizadas as seguintes análises físico-químicas: umidade, cinzas, lipídios e proteína, conforme metodologias estabelecidas nas Normas Analíticas do Instituto Adolfo Lutz (IAL, 2005). Todas as análises foram realizadas em triplicata.

Os resultados dos parâmetros de qualidade de cada uma das amostras avaliadas foram comparados com os valores declarados nos rótulos pelos respectivos fabricantes. Os resultados também foram comparados com os valores mínimos e máximos estabelecidos pelo Ministério da Agricultura, Pecuária e Abastecimento (BRASIL, 2003).

\section{Resultados e Discussão}

A Tabela 1 apresenta os resultados físico-químicos das três marcas avaliadas (codificadas pelas letras A, B e C) de rações secas para cães adultos dos tipos combate, premium e super premium comercializadas em Lajeado - RS.

Tabela 1 - Composição nutricional das rações secas para cães adultos dos tipos combate, premium e super premium adquiridas em Lajeado - RS.

\begin{tabular}{ccccc}
\hline Parâmetro (\%) & Ração & Marca A & Marca B & Marca C \\
\hline \multirow{3}{*}{ Umidade } & Combate & 8,09 & 9,42 & 10,06 \\
& Premium & 11,03 & 10,05 & 10,99 \\
& Super Premium & 9,81 & 9,72 & 9,57 \\
& Combate & 8,00 & 10,06 & 8,61 \\
Cinzas & Premium & 7,93 & 7,88 & 7,95 \\
& Super Premium & 7,87 & 7,85 & 7,93 \\
& Combate & 5,15 & 5,94 & 6,00 \\
& Lipídios & 5,27 & 5,86 & 3,39 \\
& Premium & 14,22 & 13,47 & 14,68 \\
& Super Premium & 18,64 & 19,30 & 22,40 \\
& Combate & 24,97 & 25,20 & 24,90 \\
Proteína & Premium & 27,40 & 26,38 & 26,70 \\
& Super Premium & & & \\
\hline
\end{tabular}

A análise das informações contidas nas embalagens das rações mostrou que todas apresentavam os dados de composição nutricional básica incluindo umidade, proteína bruta, extrato etéreo, matéria fibrosa, matéria mineral, cálcio e fósforo, como exigido pela legislação brasileira (BRASIL, 2009). Na avaliação de conformidade com o rótulo, todas as rações avaliadas dos segmentos combate, premium e super premium apresentaram níveis de umidade, cinzas, lipídios e proteína compatíveis com os valores declarados nas respectivas embalagens.

O mesmo não ocorreu com as amostras de rações comercializadas no Chile, avaliadas por Alvarado et al. (2008). Os autores determinaram a composição química de 26 marcas diferentes de rações secas para filhotes caninos e observaram que duas amostras analisadas apresentavam menor teor de proteína e uma continha um menor teor de gordura que os conteúdos mínimos indicados nos 
rótulos das embalagens. Isso representa uma falha no controle de qualidade das indústrias fabricantes dessas rações. As informações do rótulo, para muitos consumidores, é a fonte para uma compra segura, e no caso dos valores nutricionais declarados não serem corretos, o consumidor está sendo induzido ao erro, pois são estas informações que este utiliza como referência para comparar as rações e decidir sobre a compra. A escolha de um bom alimento para um cão é essencial para manutenção da saúde, pois através de uma nutrição adequada é possível prevenir, retardar e tratar diversas doenças (CASE et al., 1998), portanto animais que consomem diariamente rações com concentrações de proteína e lipídios abaixo do limite mínimo recomendado podem acabar apresentando problemas de saúde decorrentes do consumo de rações desbalanceadas.

A fixação de padrões de qualidade é uma maneira de diminuir a variação entre os diferentes fabricantes de rações comerciais e disponibilizar aos animais rações balanceadas que supram as necessidades nutricionais dos animais. No Brasil a Instrução Normativa $N^{\circ} 9$, de 09 de julho de 2003, fixa para alimentos secos para cães adultos, em manutenção, os seguintes valores nutricionais para os parâmetros avaliados: 12\% de umidade (máximo), 16\% de proteína bruta (mínimo), 4,5\% de lipídios (mínimo) e 12\% de cinzas (máximo) (BRASIL, 2003). Sendo que estado de manutenção, segundo Case et al. (1998), é a situação do cão que atinge seu tamanho adulto e que não está em gestação, lactação ou em trabalho. Os resultados obtidos no presente trabalho (Tabela 1) indicam que, em relação aos teores de umidade, cinzas e proteína, todas as rações estão de acordo com os parâmetros legais. Porém, uma amostra de ração do tipo premium apresentou teor de lipídios menor que o limite mínimo estabelecido pela legislação brasileira. Essas observações mostram a boa qualidade nutricional das rações comercializadas na cidade de Lajeado - RS. A qualidade nutricional de um produto é garantida através da fiscalização realizada por órgãos competentes, que no caso das rações caninas é o Ministério da Agricultura, Pecuária e Abastecimento, mas principalmente pela própria indústria fabricante por meio de um controle adequado do processo produtivo, das matérias-primas utilizadas e do produto final. A garantia de qualidade é uma forma das indústrias de rações agregarem valor aos seus produtos e ganharem a lealdade dos clientes.

Observações semelhantes também foram feitas por Carciofi et al. (2006), em estudo sobre a composição nutricional de 49 marcas de rações para cães adultos e filhotes comercializadas em Jaboticabal - SP. Os autores observaram que os valores nutricionais médios encontrados atendiam as exigências legais.

Porém, Carpim e Oliveira (2009), avaliando a qualidade nutricional de 18 rações comerciais secas para cães adultos comercializadas em Rio Verde - GO, verificaram que das dez amostras do tipo premium analisadas, $20 \%$ apresentavam teores de cinzas superiores a $12 \%$. Embora, as oito amostras do tipo econômico apresentavam teores de umidade, cinzas, lipídios e proteína em 
conformidade com os limites permitidos pela Instrução Normativa $N^{\circ}$ 9, de 09 de julho de 2003 (BRASIL, 2003).

Em relação aos resultados de umidade e cinzas (Tabela 1) das três marcas de rações não foram observadas diferenças acentuadas entre os tipos combate, premium e super premium. Os valores médios de umidade foram de 9,19;10,69 e 9,70\%, enquanto os de cinzas foram de 8,89; 7,92 e 7,88\% para as rações dos segmentos combate, premium e super premium, respectivamente. Os baixos níveis de umidade das rações caninas comercializadas em Lajeado - RS, em torno de 10\%, inibem o crescimento microbiano e, assim, evitam a sua deterioração e prolongam a vida útil; além de minimizar o problema da presença de micotoxinas (JAY, 1996; FORSYTHE, 2002; DAMODARAN et al., 2010).

Os teores de proteína e lipídios (Tabela 1) diferiram acentuadamente, principalmente entre os tipos combate e super premium. Tais diferenças são consequiência da qualidade dos ingredientes empregados em cada uma delas. Rações classificadas como super premium são assim denominadas pois são fabricadas com matérias-primas de qualidade superior, com ótimo aproveitamento pelo animal. São utilizadas proteínas de origem animal, tais como bovina, suína, de frango ou de peixe, e no caso dos vegetais são empregados os de melhor absorção pelos cães, como o arroz, por exemplo. Já as rações do tipo combate utilizam matérias-primas de qualidade inferior, como subprodutos animais (ossos, vísceras, pés, cabeça, penas, entre outros) e proteínas de origem vegetal com pouco aproveitamento, tais como trigo, soja e milho. A inclusão de subprodutos diminui a qualidade da proteína, uma vez que muitos destes não são digeridos pelo cão, não tendo por isso qualquer valor nutricional. Além disso, rações caninas elaboradas com subprodutos apresentam variação acentuada na sua composição nutricional, enquanto que a ração super premium apresenta alta qualidade e melhor perfil aminoacídico (MURRAY et al., 1997; FELICIANO et al., 2009).

Os valores médios de proteína para as rações dos segmentos combate, premium e super premium comercializadas em Lajeado - RS foram 20,11; 25,02 e 26,83\%, respectivamente. Conforme a AAFCO (2003), cães exigem altos níveis dietéticos de proteína, mínimo de $18 \%$ para cães adultos e de $22 \%$ para filhotes, portanto todas as rações analisadas estão em conformidade aos valores mínimos de proteína. Os teores médios de lipídios para as rações avaliadas no presente trabalho dos segmentos combate, premium e super premium foram 5,70; 4,84 e 14,12\%, respectivamente. Segundo Prada (2002), a ração super premium apresenta alta densidade energética, digestibilidade aparente da matéria seca superior a $85 \%$, fonte de proteína de alto valor biológico e fonte fixa de ingredientes. Os elevados teores de proteínas e lipídios das rações premium e super premium, principalmente, mostram porque uma menor quantidade das mesmas é necessária para alimentar os animais, se comparada com a ração combate. $\mathrm{O}$ consumo médio diário sugerido pelos 
fabricantes de ração do tipo combate é de aproximadamente $13,90 \%$ superior ao de ração premium, por exemplo.

As rações super premium para cães adultos comercializadas em Jaboticabal - SP analisadas por Carciofi et al. (2006), apresentaram concentrações de proteínas e lipídios de 27,8 e 15\%, respectivamente, valores semelhantes aos obtidos nesse trabalho para as amostras adquiridas em Lajeado - RS. Já Carpim e Oliveira (2009) obtiveram para as dez amostras de rações premium para cães adultos comercializadas em Rio Verde - GO teor médio de proteína de 23,20\%, valor semelhante ao das amostras desse mesmo tipo comercializadas em Lajeado - RS, porém o valor médio de lipídios de 9,87\% foi duas vezes maior que o obtido no presente trabalho. Alvarado et al. (2008) verificaram concentrações de proteína entre 23,4 - 33,2\% e de lipídios entre $10,4-18,4 \%$ para as 26 amostras de rações secas para filhotes caninos comercializadas no Chile.

\title{
4. Conclusão
}

A composição nutricional de $100 \%$ das rações secas para cães adultos dos tipos combate, premium e super premium comercializadas em Lajeado - RS estavam em conformidade com os valores indicados nos rótulos das mesmas. Apenas uma amostra estava em desacordo com o limite mínimo de lipídios estabelecido pela legislação brasileira. Os resultados obtidos indicam a qualidade dessas rações, que é de extrema importância para os cães que as consomem, uma vez que estas podem ser consideradas alimentos completos para os animais e, por isso, serem utilizadas como fonte única de alimentação para os cães, sem perigo de subnutrição.

\begin{abstract}
The production and quality of dog food in Brazil increased significantly in recent years. In Brazil the Ministry of Agriculture, Livestock and Supply is responsible for regulation of dog foods, setting quality standards in order to reduce the variation among manufacturers of commercial pet food. Therefore, the objective of this work was to evaluate the nutritional quality of dry dog foods for adult dogs combat, premium and super premium types marketed in Lajeado - RS, comparing with the values given on the labels and limits established by Brazilian legislation. For this, were collected samples of dry dog foods for adult dogs, sold in pet shops in the city, that were subjected to physical chemical analysis of moisture, ash, lipid and protein. The nutritional composition of $100 \%$ of dry dog foods for adult dogs combat, premium and super premium types was consistent with the values given on the labels of the same. The contents of protein and fat differed markedly between the three types of dog foods evaluated, especially among combat and super premium segments. Such differences are the result of the quality of ingredients used in each one. Only one sample was in disagreed with the minimum lipid established by Brazilian legislation. The results indicate the quality of dog foods, which is extremely important for dogs that consume them, since these can be considered complete food for animals and, therefore, be used as the sole source of nutrition for dogs.
\end{abstract}

Key-words: nutritional evaluation, dog food, dogs, quality. 


\section{Referências}

AAFCO - ASSOCIATION OF AMERICAN FEED CONTROL OFFICIAL. Official Publication 2003, Association of American Feed Control Official, 2003.

ALVARADO, C. A.; HODGKINSON, S. M.; ALOMAR, D.; BOROSCHEK, D. Evaluation of the chemical composition of dry dogfoods commercialized in Chile used for growing dogs. Arquivo Brasileiro de Medicina Veterinaria e Zootecnia, v. 60, n. 01, p. 218-226, 2008. DOI: 10.1590/S0102-09352008000100030.

BERTOLINO, M. T. Gerenciamento da qualidade na indústria alimentícia. Porto Alegre: Artmed, 2010.

BRASIL. Ministério da Agricultura, Pecuária e Abastecimento. Instrução Normativa No 9, de 09 de julho de 2003. Regulamento técnico sobre fixação de padrões de identidade e qualidade de alimentos completos e de alimentos especiais destinados a cães e gatos. Diário Oficial [da República Federativa do Brasil], Brasília, 14 de julho de 2003.

BRASIL. Ministério da Agricultura, Pecuária e Abastecimento. Decreto № 6296, de 11 de dezembro de 2007. Inspeção e fiscalização obrigatórias dos produtos destinados à alimentação animal. Diário Oficial [da República Federativa do Brasil], Brasília, 12 de dezembro de 2007.

BRASIL. Ministério da Agricultura, Pecuária e Abastecimento. Instrução Normativa No 30, de 05 de agosto de 2009. Estabelece critérios e procedimentos para o registro de produtos, para rotulagem e propaganda e para isenção da obrigatoriedade de registro de produtos destinados à alimentação de animais de companhia. Diário Oficial [da República Federativa do Brasil], Brasília, 07 de agosto de 2009.

CARCIOFI, A. C.; VASCONCEllos, R. S.; BORGES, N. C.; MORO, J. V.; PRADA, F.; FRAGA, V. O. Composição nutricional e avaliação de rótulo de rações secas para cães comercializadas em Jaboticabal-SP. Arquivo Brasileiro de Medicina Veterinária e Zootecnia, v. 58, n. 03, p. 421-426, 2006. DOI:10.1590/S010209352006000300021

CARPIM, W. G.; OLIVEIRA, M. C. Qualidade nutricional de rações secas para cães adultos comercializadas em Rio Verde - GO. Biotemas, v. 22, n. 02, p. 181-186, 2009.

CASE, L. P.; CAREY, D. P.; HIRAKAWA, D. A. Nutrição canina e felina: manual para profissionais. Madrid: Harcourt Brace, 1998.

DAMODARAN, S.; PARKIN, K. L.; FENNEMA, O. R. Química de alimentos de Fennema. 4 ed. Porto Alegre: ArtMed, 2010.

FELICIANO, M. A. R.; SAAD, F. M. O. B.; LOGATO, P. V. R.; AQUINO, A. A.; JOSÉ, V. A.; ROQUE, N. C. Efeitos de probióticos sobre a digestibilidade, escore fecal e características hematológicas em cães. Arquivo Brasileiro de Medicina Veterinária e Zootecnia, v. 61, n. 06, p. 1268-1274, 2009. DOI: 10.1590/S0102-09352009000600003.

FORSYTHE, S. J. Microbiologia da Segurança Alimentar. Porto Alegre: Artmed, 2002.

IAL. Instituto Adolfo Lutz. Normas Analíticas do Instituto Adolfo Lutz: Métodos Químicos e Físicos para análise de alimentos. v. 1, São Paulo: Secretaria do Estado de Saúde, 2005.

JAY, J. M. Modern Food Microbiology. 5. ed. New York: Chapman \& Hall, 1996.

MALAFAIA, M. I. F. R.; PEDROZO, E. A.; SANTOS, J. A. P.; RIBEIRO, M. D.; MALAFAIA, P.; LANA, A. M. Q. Consumo de nutrientes, digestibilidade in vivo e in vitro de dietas para cães contendo polpa de citrus e folha de alfafa. Ciência Rural, v. 32, n. 01, p. 121-126, 2002. DOI: 10.1590/S0103-84782002000100021.

MURRAY, S.; PATIL, A.; FAHEY, G.; MERCHEN, N.; HUGHES, D. Raw and rendered animal by-products as ingredients in dog diets. Journal of Animal Science, v. 75, n. 09, p. 2497-2505, 1997.

PRADA, F. Alimentos premium e superpremium para animais de estimação. In: Simpósio sobre nutrição de animais de estimação, 2002, Campinas. Anais... Campinas: CBNA, v. 2, 2002.

SINDIRAÇÕES. Indústria de rações recua $\mathbf{0 , 5 \%} \quad$ em $\quad \mathbf{2 0 0 9}$ disponível em <http://www.portaldoagronegocio.com.br/conteudo.php?id=34754>. Acesso em 04 mai. 2010. 


\section{Dados dos autores}

Nome completo: Cleimar Vedoy da Silva

Filiação institucional: Centro Universitário - UNIVATES

Departamento: Centro de Ciências Exatas e Tecnológicas - CETEC

Função ou cargo ocupado: Estudante

Endereço: Rua João Fernando Schneider, 917, Jardim do Cedro. Lajeado. RS. Brasil. CEP 95900000

Telefones para contato: (51) 84446075

e-mail: cleimar_silva@universo.univates.br ou c.subrinho@ibest.com.br

Nome completo: Francisco de Barros

Filiação institucional: Centro Universitário - UNIVATES

Departamento: Centro de Ciências Exatas e Tecnológicas - CETEC

Função ou cargo ocupado: Estudante

Endereço: Rua Afonso Bruno Eckerth, 64, Bairro Alto da Bronza. Estrela. RS. Brasil. CEP 95880000

Telefones para contato: (51) 3720 1159, (51) 99631571

e-mail: chicobarros@universo.univates.br

Nome completo: Claucia Fernanda Volken de Souza

Filiação institucional: Centro Universitário - UNIVATES

Departamento: Centro de Ciências Exatas e Tecnológicas - CETEC

Função ou cargo ocupado: Professora adjunta

Endereço: Rua Senador Salgado Filho, 257/404, Centro. Esteio. RS. Brasil. CEP 93260-140.

Telefones para contato: (51) 37147000

e-mail: clauciavolken@ig.com.br ou clauciavolken@bol.com.br 